\title{
ESR technique for noninvasive way to quantify cyclodextrins effect on cell membranes
}

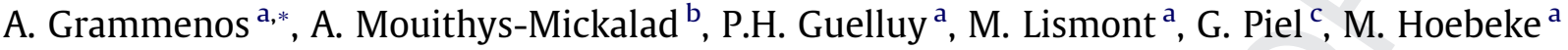 \\ ${ }^{a}$ Laboratory of Biomedical Spectroscopy, Department of Physics, B5, University of Liège, Sart-Tilman, Belgium \\ ${ }^{\mathrm{b}}$ Center of Oxygen, Research and Development (CORD), Department of Chemistry, B6a, University of Liège, Sart-Tilman, Belgium \\ ${ }^{c}$ Laboratory of Pharmaceutical Technology, Department of Pharmacy, CHU, B36, University of Liège, 1 Av. de l'Hopital, Belgium
}

\section{A R T I C L E I N F O}

\section{Article history:}

Received 11 June 2010

Available online $\mathrm{xxxx}$

\section{Keywords:}

Cholesterol

Cyclodextrin

ESR

Lipid rafts

Membrane viscosity

Spin label

\begin{abstract}
A B S T R A C T
A new way to study the action of cyclodextrin was developed to quantify the damage caused on cell membrane and lipid bilayer. The Electron Spin Resonance (ESR) spectroscopy was used to study the action of Randomly methylated-beta-cyclodextrin (Rameb) on living cells (HCT-116). The relative anisotropy observed in ESR spectrum of nitroxide spin probe (5-DSA and cholestane) is directly related to the rotational mobility of the probe, which can be further correlated with the microviscosity. The use of ESR probes clearly shows a close correlation between cholesterol contained in cells and cellular membrane microviscosity. This study also demonstrates the Rameb ability to extract cholesterol and phospholipids in timeand dose-dependent ways. In addition, ESR spectra enabled to establish that cholesterol is extracted from lipid rafts to form stable aggregates. The present work supports that ESR is an easy, reproducible and noninvasive technique to study the effect of cyclodextrins on cell membranes.
\end{abstract}

(c) 2010 Published by Elsevier Inc.

\section{Introduction}

Cyclodextrins (CD) are widely used in the pharmaceutical field and known for their ability to increase the aqueous solubility and the chemical stability of different drugs [1,2]. There are three types of natural CDs which are formed by six, seven or eight D-glucopyranose units denominated, respectively as $\alpha-, \beta-$ and $\gamma-C D$. These molecules look like truncated cones constituted by an inner internal hydrophobic cavity and a hydrophilic surface. Among them, $\beta$ CD derivatives ( $\beta$-CDs) are known to possess the efficacy to make complexes with several drugs [1]. Within this family, the Randomly methylated $\beta-C D$ derivative (Rameb) has received much attention and has shown a great pharmaceutical interest as it is efficient for its ability to penetrate through nasal mucosa [3] and skin [4].

Therefore, Rameb can readily enter in the composition of different nasal spray (for instance estradiol nasal spray sold as Aerodiol ${ }^{\circledR}$ in Europe). Even if this kind of CDs is one of the most studied and commercialized for its ability to enhance drug delivery, Rameb might still be of a great interest when investigating various membranes.

Numerous works have demonstrated that the plasma membrane contains different domains [5-9], indicating that membranes cannot be defined by only the fluid mosaic model as described by

\footnotetext{
* Corresponding author. Fax: +32 (0) 43663629.

E-mail address: A.Grammenos@ulg.ac.be (A. Grammenos)
}

Singer and Nicholson [10]. Recently, it was highlighted that cholesterol distribution in the membrane is heterogeneous and concentrated in cholesterol- and sphingomyelin-rich domains (lipid rafts). These lipid rafts are involved in significant cell function and can be isolated in the form of patches resistant to cold non ionic detergent $[5,11]$.

However, the existence of these domains is still the subject of an intense debate in the scientific community and their morphology, size, density and molecular composition are also under consideration. Known for their cholesterol affinity, the $\beta$-CDs like Rameb [3,12] may interact with lipid rafts and could become an interesting tool to understand the function of lipid rafts.

The most common way to quantify the cholesterol depletion due to $\beta$-CDs is to make a lipid extraction and use a cholesterol assay kit [13]. In order to obtain the percentage of cholesterol into the membrane rafts which are identified as low density membrane fraction, a separation of these domains is generally realized by a sucrose gradient (with or without detergent extraction) [14]. One of the main disadvantages of the cholesterol extraction is that different amounts of cholesterol are obtained depending on the experimental protocol used to isolate the membrane [14]. Electron Spin Resonance (ESR) is a unique technique able to provide information about the structure and the dynamics of biological systems in a noninvasive way [15]. However, despite this great advantage, no study has been undertaken by ESR to accurately investigate the interaction between $\beta$-CDs and membranes. The present work demonstrates that ESR is an easy and reproducible technique to 
quantify the damage caused by the $\beta$-CDs and could be a new advantageous tool for a better understanding of these actions on cell membrane.

\section{Materials and methods}

\subsection{Cell cultures}

The human colon carcinoma (HCT-116) cell line was cultured in Dulbecco's modified Eagle's medium (DMEM, Invitrogen, Belgium) supplemented with $10 \%$ fetal calf serum (Invitrogen, Belgium), $2 \mathrm{mM}$ of L-glutamine, penicillin $(100 \mathrm{U} / \mathrm{ml})$, streptomycin $(100 \mathrm{U} /$ $\mathrm{ml}$ ) (Invitrogen, Belgium) and was maintained in a humidified $37^{\circ} \mathrm{C}, 5 \% \mathrm{CO}_{2}$ incubator. Cells were not used at passages higher than 20.

\subsection{Exposure of HCT-116 cells to Randomly methylated $\beta$-cyclodextrin (Rameb)}

Cells from two T175 flasks (90\% confluent) were collected by trypsinization, centrifuged for $7 \mathrm{~min}$ at $240 \mathrm{~g}$ and suspended in $10 \mathrm{ml}$ of medium (DMEM) containing Randomly methylated $\beta$ cyclodextrin (Rameb) which was sterilized by filtration in aseptic conditions at desired concentration. The cells $\left(15 \times 10^{6}\right)$ were then incubated at $37^{\circ} \mathrm{C}$ for $1 \mathrm{~h}$ in a humidified atmosphere with $5 \%$ of $\mathrm{CO}_{2}$. Rameb was obtained from Wockes Chemie $\mathrm{GmbH}$ (Munich, Germany).

\subsection{Cell viability}

After 1 and $2 \mathrm{~h}$ of Rameb incubation $(10 \mathrm{mM})$, as described above, cells were centrifuged for $5 \mathrm{~min}$ at $200 \mathrm{~g}$ and the pellet was resuspended in $10 \mathrm{mM}$ of fresh DMEM. The cell viability was then determined using both a Cell Proliferation Reagent WST-1 (Roche, Germany) and the Trypan blue dye exclusion assay.

In order to perform the WST- 1 cell viability assay according to the manufacturer instructions [16], the cells $\left(10^{4}\right.$ cells by well by $100 \mu \mathrm{l})$ were placed in microtiter plates $(10 \mathrm{~min}$ after $1 \mathrm{~h}$ period of incubation). Absorbance of the colored formazan was determined using an automated microplate reader at $450 \mathrm{~nm}$ wavelength. The mean absorbance of control wells (cells not incubated with Rameb) represented $100 \%$ cell viability. Viability of cells treated with Rameb was measured in triplicate and compared to the absorbance of control cells.

\subsection{Cell sample preparation for ESR measurements}

It is known that addition of $\beta$-CDs to membrane models expels phospholipids $[3,17,18]$. Consequently stearic acid derivative labeled by stable doxyl radical ring ( $n$-DSA) is also expelled out of the cell membrane (see results, Fig. 1). This property helped us to define an appropriate protocol in order to measure the microviscosity. The $1 \mathrm{~h}$ incubation of cells with Rameb (as described above) was ended by centrifugation for $5 \mathrm{~min}$ at $200 \mathrm{~g}$. After dilution of the cell pellet in $1 \mathrm{ml}$ of sterile phosphate buffer saline solution (PBS), an amount of stearic acid derivative labeled by stable doxyl radical ring at the C-5 level (5-DSA) (Aldrich, USA) was added to achieve $10^{-4} \mathrm{M}$ concentration and incubated less than 5 min. A 5-DSA stock solution was first obtained in ethanol $\left(10^{-2} \mathrm{M}\right)$ and the added 5DSA solution was less than $1 \%$ of total volume. Final solutions were then transferred into a quartz cell $(500 \mu \mathrm{l})$ for ESR measurements.

$3 \beta$-Doxyl-5 $\alpha$-cholestane (cholestane) (Sigma, USA) dissolved in chloroform was also used as a probe on HCT-116 membranes. In these experiments, collected and centrifuged cells $\left(15 \times 10^{6}\right)$ were suspended in $1 \mathrm{ml}$ of PBS containing $10^{-4} \mathrm{M}$ cholestane and incu-
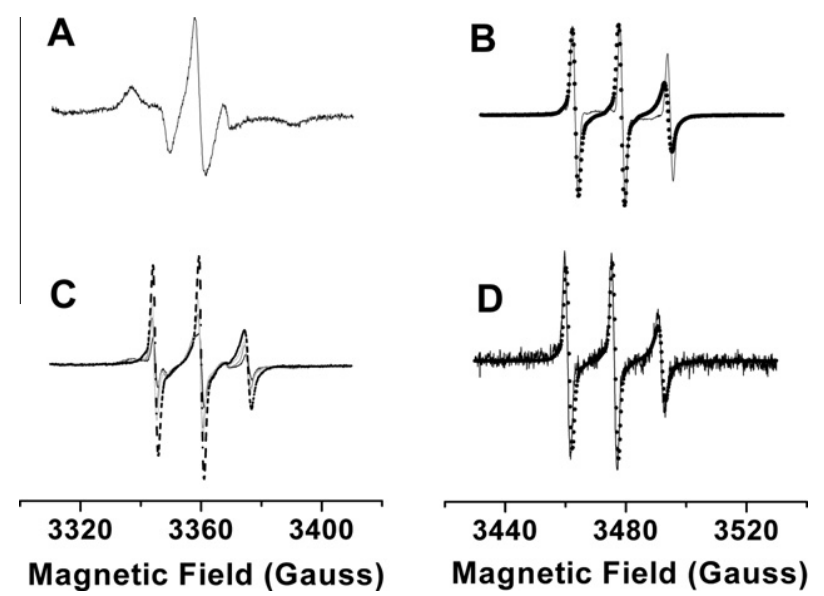

Fig. 1. Rameb influence on 5-DSA ESR spectra: (A) $0.001 \mathrm{M}$ 5-DSA in cells membrane. (B) $0.001 \mathrm{M}$ 5-DSA dissolved in PBS (full line) or in PBS containing $10 \mathrm{mM}$ of $\mathrm{CD}$ (dotted line). (C) Spectral ESR evolution of 5-DSA initially embedded in cell membranes and incubated with $1.5 \mathrm{mM}$ (black line), $2 \mathrm{mM}$ (gray line), $6 \mathrm{mM}$ (light gray line) and $10 \mathrm{mM}$ of Rameb (dotted line). (D) ESR spectrum of 5-DSA in the supernatant of cells incubated with $10 \mathrm{mM}$ of $\mathrm{CD}$ (full line) and 5-DSA solubilized in PBS containing $10 \mathrm{mM}$ of $\mathrm{CD}$.

bated for $10 \mathrm{~min}$. The incubation was ended by the addition of sterilized stock Rameb solution $\left(10^{-1} \mathrm{M}\right.$ in PBS) to achieve the final concentration of $2.5 \times 10^{-3} \mathrm{M}$. HCT-116 suspensions were then transferred into a quartz flat ESR cell.

\subsection{Liposome preparation}

Lipid vesicles were prepared from Dimyristoylphosphatidylcholine (DMPC) (Sigma, USA) and cholesterol (CHOL) (Merck, Germany). Made from DMPC:CHOL (70:30 mol\%), the liposomes were prepared by hydratation of lipid films. Briefly, the required amount of lipids $(3.51 \mathrm{mg} / \mathrm{mL}$ of DMPC and $0.86 \mathrm{mg} / \mathrm{mL}$ of CHOL) was dissolved in chloroform. The total lipid cholesterol concentration was $7.4 \mathrm{mM}$. The mixture was then stirred for $5 \mathrm{~min}$ and the solvent was evaporated under vacuum. The resulting lipid film was suspended in PBS pH $7.0\left(1 / 15 \mathrm{M}\right.$; $\mathrm{Na}_{2} \mathrm{HPO}_{4}-\mathrm{KH}_{2} \mathrm{PO}_{4}$, from Riedel-de Haën, Belgium) at $35^{\circ} \mathrm{C}$, and stirred by vortex mixer in order to obtain large multilamellar vesicles (MLV) [19]. The MLV suspensions were transferred into an extruder (Lipex Biomembrane, Canada), in which the unilamellar liposomes were formed by passing the suspensions through polycarbonate filters $(0.1 \mu \mathrm{m}$ pore size, Nucleopore, CA), under a pressure up to $6895 \mathrm{~Pa}$ of nitrogen (Air Liquid, Belgium). The procedure was repeated 10 times at $35^{\circ} \mathrm{C}$ and resulted in unilamellar liposomes [20]. Once the liposomes were made, cholestane (stock solution in chloroform $\left(10^{-1} \mathrm{M}\right)$ ) was added and the final solution $\left(10^{-4} \mathrm{M}\right)$ was then transferred for ESR experiments.

\subsection{ESR experimental conditions}

All ESR experiments were performed at $9.56 \mathrm{GHz}$ using a Bruker ESR 300E spectrometer (Bruker, Karlshrure-Germany) equipped with a variable temperature controller accessory and operating at center field strength of $3480 \mathrm{G}$ with $100 \mathrm{G}$ as sweep width, modulation amplitude of $2.55 \mathrm{G}$ and $20.2 \mathrm{~mW}$ microwave power. The time constant and the conversion time were respectively 2.56 and $163.84 \mathrm{~ms}$. Three scans were acquired for each measurement.

\subsection{ESR spectra simulation}

ESR $n$-DSA modeling spectra were carried out according to the method reported by Arsov et al. [21,22]. The experimentally ac- 
quired spectra were simulated using the software EPRSIM (version 4.99 2005). The spectrum-simulation model assumes that each spectrum can be a superimposition of the spectral components that identify the membrane heterogeneity. Each component reflects the properties of a particular domain type which is highlighted by the values of the chosen parameter set. This one corresponds to order parameter $S$, effective rotational correlation time $\tau_{c}$, hyperfine and Zeeman tensor's polarity correction factors and weighing factors $w$.

\subsection{Microviscosity determination}

The mobility of $n$-DSA in the explored medium (liposomes and HCT-116 cells) was quantified by order parameter $(S)$ as described in point 2.4. In the case of weakly to moderately immobilized probes $\left(\tau_{\mathrm{c}}<3 \times 10^{-9} \mathrm{~s}\right) \tau_{\mathrm{c}}$ is used, whereas, for strongly immobilized labels $\left(\tau_{\mathrm{c}}>3 \times 10^{-9} \mathrm{~s}\right), S$ is better suited $[23,24]$. Previously established standard curves of microviscosity versus correlation time or order parameter [25] were used to convert measured parameters into membrane microviscosity. Each measure was repeated at least five times and microviscosity standard deviation was calculated to be $3 \%$.

\subsection{Membrane cholesterol measurement}

Cells from two T175 flasks (90\% confluent) were collected by trypsinization, centrifuged for $7 \mathrm{~min}$ at $240 \mathrm{~g}$ and suspended in $10 \mathrm{ml}$ DMEM containing Rameb sterilized by filtration in aseptic conditions at desired concentration. The cells $\left(15 \times 10^{6}\right)$ were then incubated at $37{ }^{\circ} \mathrm{C}$ for $1 \mathrm{~h}$ in a humidified atmosphere with $5 \%$ of $\mathrm{CO}_{2}$. The $1 \mathrm{~h}$ incubation was ended by centrifugation during $5 \mathrm{~min}$ at $200 \mathrm{~g}$ in order to remove the Rameb. The cell pellet was then suspended in DMEM to be able to count the required amount of cells to perform a lipidic extraction. Briefly, cells $(750,000)$ were put in contact with $300 \mu$ of $1 \%$ Triton distilled in water. After 5 min of incubation, $1.8 \mathrm{ml}$ of a chloroform/methanol (2:1) mixture was added. The mixture was stirred for $10 \mathrm{~min}$. To obtain a good phase separation, $300 \mu \mathrm{l}$ of Tris $(0.2 \mathrm{M})$ at $\mathrm{pH} 6.5$ was added, and the mixture was centrifuged for $10 \mathrm{~min}(240 \mathrm{~g})$ at $37^{\circ} \mathrm{C}$. To isolate the lipidic phase, the chloroform phase was recovered and evaporated under a flow of nitrogen. The membrane cholesterol levels were then measured using an Amplex Red Cholesterol Assay Kit according to the manufacturer's instructions (Molecular Probes). Briefly, the membrane fractions were dissolved within $800 \mu \mathrm{l}$ of buffer (PBS, pH 7.4) then incubated with Amplex Red reaction mixture for $30 \mathrm{~min}$ at $37^{\circ} \mathrm{C}$ and analyzed using a fluorimeter with an excitation wavelength of $570 \mathrm{~nm}$ and emission wavelength of $590 \mathrm{~nm}$.

\section{Results and discussion}

\subsection{Cell viability study}

Based on WST-1 assay, fluorometric measurements revealed that the cell viability was more than $94 \%$ after an incubation of the highest concentration of Rameb $(10 \mathrm{mM})$ for 1 and $2 \mathrm{~h}$ (data not shown). Moreover, at the concentration used to obtain an optimized ESR signal ( $10^{-4}$ M 5-DSA), no cytotoxic effect of the spin probe was observed ( $98 \%$ of cell viability). These results were also confirmed by Trypan blue exclusion assay. It is important to notice that another type of cell could reveal much higher mortality with similar concentration of Rameb [13].

\subsection{Effects of Rameb on 5-DSA probe}

Stearic spin labels (5-DSA) were used as probes to analyze the interaction between Rameb and the cell membrane fluidity. Spec- trum on Fig. 1A is characteristic of a probe which invested the hydrophilic cell membrane compartment at $25^{\circ} \mathrm{C}$ [26].

Fig. 1B highlights the affinity of the 5-DSA with the Rameb. Indeed, a significant difference has been observed between the probe spectrum in PBS (Fig. 1B, full line) and the one obtained for 5-DSA in PBS containing Rameb (Fig. 1B, dotted line) which is asymmetric and distorted; such a spectrum is characteristic of probe aggregates in micelle structures as previously reported $[17,27,28]$.

The addition of increasing concentrations of Rameb (1.5, 2, 6 and $10 \mathrm{mM}$, respectively) to HCT-116 cells containing 5-DSA induces a progressive transformation of the ESR spectrum (Fig. 1C) which tends to be similar to the spectrum shown in Fig. 1B (dotted line). This result reveals that the Rameb affinity with 5-DSA is strong enough to lead to the extraction of all the probes initially embedded in the membrane bilayer and that the extracted probe is not free in solution but aggregates in micellar structure. This was confirmed by the analysis of the ESR spectrum of the cell supernatant that has been in contact with Rameb (Fig. 1D, full line) which is similar to the 5-DSA spectrum in PBS and containing Rameb (Fig. 1D, dotted line).

Fig. 1C also puts in evidence that 5-DSA are extracted in a dosedependent way. Indeed, the highest the Rameb concentration is, the most intense the three peaks of the ESR spectrum are.

A spectral simulation has been done to confirm this behavior (Fig. 2A-a and B-a, gray line). The simulated spectrum of 5-DSA incorporated into cell membranes, which were in contact with $1.5 \mathrm{mM}$ of Rameb, corresponds to the addition of two components characteristic of two different domains. The first one (Fig. 2A-1b) corresponds to probes embedded into the cell membrane and the second domain (Fig. 2A-2b) to probes extracted from the cell membrane and aggregated within micelles ( $20 \%$ for this Rameb concentration). The spectral simulation obtained with cell membranes in contact with $10 \mathrm{mM}$ of Rameb has only one component indicating that all the probes are extracted from the membrane (Fig. 2B-b). This result is consistent with the fact that Rameb acts in a dosedependent manner.

\subsection{Effects of Rameb on cholestane probes}

The ESR spin labeling method relies on the presence of probes inside the bilayer. The $n$-DSA spin label (which has almost the

A

B
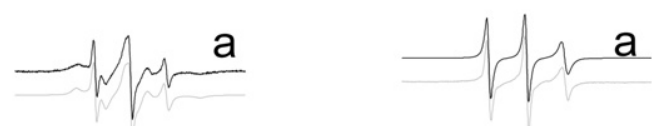

1
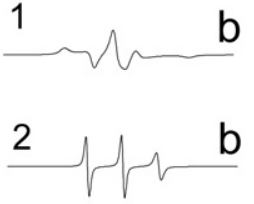

b
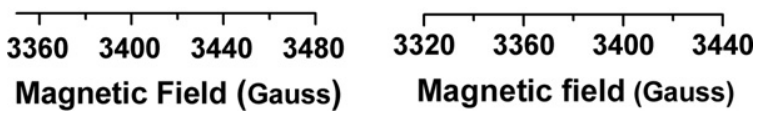

Fig. 2. ESR spectra of 5 -DSA in the supernatant of cells being in contact with $1.5 \mathrm{mM}$ (A) and $10 \mathrm{mM}$ of Rameb (B). (a) Black line: experimental spectrum. Gray line: the best fit to the experimental spectrum, taking into account the superimposition of possible coexisting domains shown in (b). (b) A: computer simulation of the specific spectra of the two coexisting domains explored by the 5-DSA: 1 ; first domain $(S=0.906, \tau=0.419 \mathrm{~ns}, \quad W=0.702), 2$; second domain $(S=0.631$, $\tau=0.557 \mathrm{~ns}, W=1.714)$. (b) B: computer simulation of the specific spectrum of the only one domain $(S=0.028, \tau=0.557 \mathrm{~ns}, W=0.728)$ explored by the probe. 
same behavior as the phospholipids) has been first used, confirming that the Rameb is able to interact with them. To better apprehend the CDs action on membranes another kind of probe has been used: the cholestane, a membrane spin label with a chemical structure similar to cholesterol.

Fig. 3A shows the ESR spectrum of cholestane embedded in cell membrane (light gray line). The large distorted peak observed results in an important spin-spin nitroxide interaction favoured by a high local concentration of cholestane. Available knowledge indicates that cellular membranes manage their vast chemical diversity by sorting into specialized microdomains [29] which are referred to under the general heading of lipid raft. Cholesterol plays a fundamental role in maintaining their structure and function [30]. The cholestane spin probe probably lies close to each other in these lipid rafts, leading to this kind of self-broadening.

To support this hypothesis, DMPC liposomes doped with $30 \%$ of cholesterol and containing cholestane have been prepared (Fig. 3B). These structures have been made to incorporate the cholesterol uniformaly in the membrane (no raft). The corresponding ESR spectrum is reported in Fig. 3B; no broad peak as in Fig. 3A is observed indicating that probes are not close to each other like in cell membrane. This result tends to confirms that cholesterol might be organized in rafts within cell membrane and that cholestane like cholesterol has an affinity for these microdomains. As probe and cholesterol have almost similar chemical structure, the cholestane probably reflects the cholesterol behavior.

The evolution of probe ESR spectrum in cells incubated with Rameb (Fig. 3A) clearly demonstrates that cholestane is no more embedded in membrane. The resulting spectrum is close to the spectrum of cholestane solubilized in PBS containing Rameb (Fig. 3C dotted line). The difference between cholestane ESR spectrum in PBS and the one obtained in PBS containing Rameb (Fig. 3C) reflects once again the ability of Rameb to form micellar aggregates with the probes. To sum up, ESR results show that Rameb not only extracts different components from the plasma membrane to form stable aggregates but it is also able to interact with lipid rafts.

\subsection{Effects of Rameb on membrane microviscosity}

As cholesterol and phospholipids are essential constituents of the membrane, their extraction ought to necessarily affect the degree of order of the bilayer, and so the microviscosity.

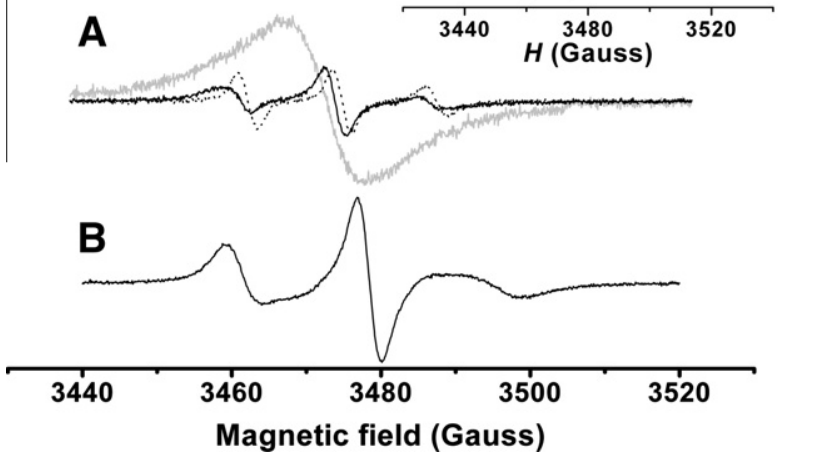

Fig. 3. (A) ESR spectra of cholestane $(0.1 \mathrm{mM})$ in cell membrane (gray line), in cell membrane being in contact with $2.5 \mathrm{mM}$ of $\mathrm{CD}$ (black line) and solubilized in PBS containing $2.5 \mathrm{mM}$ of $\mathrm{CD}$. (B) Spectrum of cholestane $(0.1 \mathrm{mM})$ embedded in liposomial bilayer (70:30 mol\%). (C) Spectra of cholestane $(0.1 \mathrm{mM})$ solubilized in PBS (black line) and in PBS containing $2.5 \mathrm{mM}$ of Rameb (dotted line).

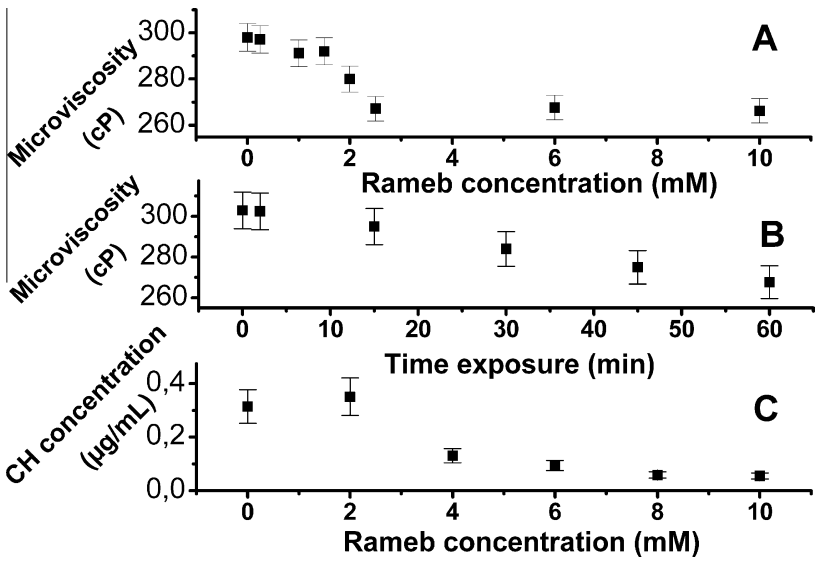

Fig. 4. (A) Influence of various concentrations of Rameb $(0,0.25,1,1.5,2,2.5,6$ and $10 \mathrm{mM}$ ) on the microviscosity of HCT-116 membranes. Cells have been in contact with the $\mathrm{CD}$ during $1 \mathrm{~h}$ at $37^{\circ} \mathrm{C}$. (B) Influence of $6 \mathrm{mM}$ Rameb time exposure on microviscosity of cell membranes. (C) Residual cholesterol content of HCT-116 after treatment with various concentrations of Rameb $(0,2,4,6,8$ and $10 \mathrm{mM})$ for $1 \mathrm{~h}$ at $37^{\circ} \mathrm{C}$.

Fig. 4A shows the microviscosity sensed by 5 -DSA probes incorporated in HCT-116 cell membrane in function of the Rameb concentration. In the absence of Rameb, the microviscosity measured on HCT-116 membrane, near the polar head group, is $298 \mathrm{cP}$. This value decreases as the Rameb concentration increases and stabilizes when reaching $265 \mathrm{cP}$ at $2.5 \times 10^{-3} \mathrm{M}$ of cyclodextrin. Up to $10^{-2} \mathrm{M}$ of Rameb, the microviscosity remains nearly constant.

Fig. 4B puts in evidence the microviscosity sensed by 5-DSA probes incorporated in HCT-116 cell membrane as a function of time exposure for unique Rameb concentration of $6 \mathrm{mM}$. It appears that the more the cyclodextrin is in contact with the cells the more the microviscosity is low. A linear decrease of $35 \mathrm{cP}$ is measured during the first hour.

In order to correlate this microviscosity decrease with the membrane cholesterol extraction, the membrane cholesterol concentration was measured using a cholesterol assay kit.

Fig. 4C shows that the cholesterol concentration of cells without Rameb is $0.31 \pm 0.06 \mu \mathrm{g} / \mathrm{mL}$. This concentration decreases when cells were incubated in presence of Rameb. Beyond an exposure of $6 \mathrm{mM}$ of $\mathrm{CD}$, the cholesterol level remains nearly constant $(0.054 \pm 0.011 \mu \mathrm{g} / \mathrm{mL})$. The comparison between Fig. 4A and $\mathrm{C}$ clearly shows that the microviscosity and the cellular concentration of cholesterol decrease with a similar Rameb dose dependence, supporting the hypothesis that the membrane microviscosity is directly linked to the cholesterol cell concentration. ESR microviscosity results corroborate our previous work using liposomes as a membrane model and confirm that the cholesterol extraction due to the Rameb is the major cause of the membrane microviscosity decrease [17].

\section{Conclusions}

This study allows to confirm the ability of Rameb to extract cholesterol and 5-DSA in cells in a dose-dependent way. ESR results demonstrate that the extracted cholesterol and 5-DSA formed stable aggregates and that the lipid rafts micodomain are damaged by the $\mathrm{CD}$. Moreover, this work shows that the membrane microviscosity is directly linked to the cholesterol content of the cell. Interestingly, based on our ESR results, Rameb appears as efficient agent to extract cholesterol depending on time and concentration. In summary, this study has demonstrated that ESR is an easy and reproducible tool able to give a lot of information on the ability of a drug to interact with cell membranes. 


\section{Acknowledgments}

A special thanks to Zoran Arsov, from the Departement of Solid State Physics ("Jozef Stefan" Institute, Ljubljana, Slovenia), for his advices in terms of expert knowledge in the field of evolutionary optimization.

\section{References}

[1] T. Loftsson, M.E. Brewster, Pharmaceutical application of cyclodextrins. 1. Drug solubilisation and stabilization, J. Pharm. Sci. 85 (1996) 1017-1024.

[2] T. Loftsson, Cyclodextrin in skin delivery, Cosmet. Toiletries 115 (10) (2000) 59-66.

[3] L. Boulmedarat, G. Piel, A. Bochot, S. Lesieur, L. Delattre, E. Fattal, Cyclodextrinmediated drug release from liposomes dispersed within a bioadhesive gel, Pharm. Res. 22 (2005) 962-970.

[4] G. Piel, S. Moutard, E. Uhoda, F. Pilard, G.E. Piérard, B. Perly, L. Delattre, B. Evrard, Skin compatibility of cyclodextrins and their derivative: a comparative assessment using a corneoxenometry bioassay, Eur. J. Pharm. Biopharm. 57 (2004) 479-482.

[5] K. Simons, E. Ikonen, Functional rafts in cell membranes, Nature 387 (1997) 569-572.

[6] L.D. Zajchowski, S.M. Robbins, Lipid rafts and little caves, Eur. J. Biochem. 269 (2002) 737-752

[7] W.K. Subczynski, A. Kusumi, Dynamics of raft molecules in the cell and artificial membranes: approaches by pulse EPR spin labeling and single molecule optical microscopy, Biochem. Biophys. Acta 1610 (2003) 231-243.

[8] M.G. Rivas, A.M. Gennarlo, Detergent resistant domains in erythrocyte membranes survive after cell cholesterol depletion: an EPR spin label study, Chem. Phys. Lipids 122 (2003) 165-169.

[9] K. Kawasaki, W.K. Subczynski, J.S. Hyde, A. Kusumi, Pulse EPR detection of lipid exchange between protein-rich raft and bulk domains in the membrane: methodology development and its application to studies of influenza viral membrane, Biophys. J. 80 (2001) 738-748.

[10] S.J. Singer, GL. Nicholson, The fluid mosaic model of the structure of cell membranes, Sciences 175 (1972) 720-731.

[11] N.M. Hopper, Detergent-insoluble glycosphingolipid/cholesterol-rich membrane domains, lipid rafts and caveolae, Mol. Membr. Biol. 16 (1999) 145-156.

[12] G. Piel, M. Piette, V. Barillaro, D. Castagne, B. Evrard, L. Delattre, Study of the relationship between lipid binding properties of cyclodextrin and their effect on the integrity of liposomes, Int. J. Pharm. 338 (2007) 35-42.

[13] D. Castagne, M. Fillet, L. Delattre, B. Evrard, B. Nusgens, G. Piel, Study of the cholesterol extraction capacity of $\beta$-cyclodextrin and its derivatives, relationships with their effects on endothelial cell viability and on membrane models, J. Incl. Phenom. Macrocycl. Chem. 63 (2008) 225-231.
[14] R. Zidovetzki, I. Levitan, Use of cyclodextrins to manipulate plasma membrane cholesterol content: evidence, misconceptions and control strategies, Biochim. Biophys. Acta 1768 (2007) 1311-1324.

[15] K. Witold, Subczynski, A. Kusumi, Dynamics of raft molecules in the cell and artificial membranes: approaches by pulse EPR spin labelling and single optical microscopy, Biochim. Biophys. Acta 1610 (2003) 231-243.

[16] H. Suttmann, M. Retz, F. Paulsen, J. Harder, U. Zwergel, J. Kamradt, B. Wullich, G. Unteregger, M. Stöckle, J. Lehmann, Antimicrobial peptides of the Cecropinfamily show potent antitumor activity against bladder cancer cells, BMC Urol. 8 (2008) $1-7$

[17] A. Grammenos, M.A. Bahri, P.H. Guelluy, G. Piel, M. Hoebeke, Quantification of Randomly-methylated- $\beta$-cyclodextrin effect on liposome: an ESR study, Biochem. Biophys. Res. Commun. 390 (2009) 5-9.

[18] G. Piel, M. Piette, V. Barillaro, D. Castagne, B. Evrard, L. Delattre, Betamethasone-in-cyclodextrin-in-liposomes: the effect of cyclodextrins on encapsulation efficiency and release kinetics, Int. J. Pharm. 312 (2006) 75-82.

[19] L. Coderch, J. Fonollosa, M. De Pera, J. Estelrich, A. De La Maza, J.L. Parra, Influence of cholesterol on liposome fluidity by EPR relationship with percutaneous absorption, J. Controlled Release 68 (2000) 85-95.

[20] F. Olson, C.A. Hunt, F.C. Szoka, W.J. Vail, D. Papahadjopoulos, Preparation of liposomes of defined size distribution by extrusion through polycarbonate membranes, Biochim. Biophys. Acta 557 (1979) 9-23.

[21] Z. Arsov, J. Strancar, Determination of partition coefficient of spin probe between different lipid membrane phases, J. Chem. Inf. Model. 45 (2005) 1662-1667.

[22] Z. Arsov, M. Schara, M. Zorko, J. Strancar, The membrane lateral domain approach in the studies of lipid-protein interaction of GPI-anchored bovine erythrocyte acetylcholinesterase, Eur. Biophys. J. 33 (2004) 715-725.

[23] H.M. McConnell, W.L. Hubell, Molecular motion in spin-labeled phospholipids and membranes, J. Am. Chem. Soc. 93 (1971) 314-326.

[24] N.S.P. Deo, Electron spin resonance study of phosphatidylcholine vesicles using 5-doxyl stearic acid, Colloids Surf. B 25 (2002) 225-232.

[25] M.A. Bahri, B.J. Heyne, P. Hans, A.E. Seret, A.A. Mouithys-Mickalad, M.D. Hoebeke, Quantification of lipid bilayer effective microviscosity and fluidity effect induced by propofol, Biophys. Chem. 114 (2005) 53-61.

[26] L. Coderch, J. Fonollosa, M. De para, J. Estelrich, A. De La Maza, J.L. Parra, Influence of cholesterol on liposome fluidity by EPR relationship with percutaneous absorption, J. Controlled Release 68 (2000) 85-95.

[27] E. Mileo, P. Franchi, R. Gotti, C. Bendazzoli, E. Mezzina, M. Lucarini, An EPR method for measuring the rate of distribution of organic substrates between cyclodextrin, micelles and water, Chem. Commun. (2008) 1311-1313.

[28] M.A. Bahri, M. Hoebeke, A. Grammenos, L. Delanaye, N. Vandewalle, A. Seret, Investigation of SDS, DTAB and CTAB micelle microviscosities by electron spin resonance, Colloids Surf. A 290 (2006) 206-212.

[29] L. Weglarz, A. Koceva-Chyla, K. Gwodzdzinski, Z. Dzierzewics, Z. Jozwiak, Evaluation of hydralazine and procainamide effects on fibroblast, Biochem. J. 85 (2003) 549-556.

[30] D.H. Nguyen, D. Taub, Cholesterol is essential for macrophage inflammatory protein $1 \mathrm{~b}$ binding and conformation integrity of CC chemokine receptor 5 , Blood 12 (2002) 4298-4360. 